\title{
Current state of Industrial Symbiosis and Energy Efficiency in the European energy intensive sectors ${ }^{\text {h/ }}$
}

\author{
Teresa Annunziata Branca ${ }^{1}(\mathbb{D})$, Valentina $_{\text {Colla }}{ }^{1,}{ }^{*}$ (D), Barbara Fornai $^{1}$, Alice Petrucciani ${ }^{1}$ (D), Maria Ilaria Pistelli ${ }^{2}$ (D),
} Eros Luciano Faraci ${ }^{2}$, Filippo Cirilli ${ }^{2}$, and Antonius Johannes Schröder ${ }^{3}$

${ }^{1}$ Scuola Superiore Sant'Anna, TeCIP Institute, ICT-COISP Center, Pisa, Italy

${ }^{2}$ RINA CONSULTING - Centro Sviluppo Materiali S.p.A. (CSM), Rome, Italy

3 Technische Universität Dortmund, Dortmund, Germany

Received: 24 August 2021 / Accepted: 9 February 2022

\begin{abstract}
The implementation of Industrial Symbiosis and Energy Efficiency is linked to the ongoing technological development. New technologies can lead to an increased up-take of these concepts, which affect all areas of process industries and involve the whole workforce. The present paper describes part of the work developed in the early stage of a current Erasmus + project entitled "Skills Alliance for Industrial Symbiosis: A Cross-sectoral Blueprint for a Sustainable Process Industry (SPIRE-SAIS)". Such project aims at developing an industry-driven and proactive skills strategy to assist the implementation and exploitation of Industrial Symbiosis and Energy Efficiency across the energy-intensive industrial sectors, which are represented by the association of Sustainable Process Industry through Resource and Energy Efficiency (SPIRE). The main aspects of the current state of implementation of Industrial Symbiosis and Energy Efficiency in European process industries are analyzed. In addition, upcoming techniques and developments are taken into account for the main considered sectors, e.g., Iron and Steel, Chemical, Non-ferrous Metals, Mineral, Water, Ceramics, and Cement. Achieved results on implementation of technologies and practices based on Industrial Symbiosis and Energy Efficiency, as well as new challenges coming from their accomplishments are considered. Companies' perceptions on future implementation of Industrial Symbiosis and Energy Efficiency are explored, together with possible barriers resulting in implementation practices and expected solutions to satisfy related ongoing and future skill demands.
\end{abstract}

Keywords: industrial symbiosys / energy efficiency / energy intensive industry / vocational education and training / skills

\section{Introduction}

The concepts of Industrial Symbiosis (IS) and Energy Efficiency (EE) are receiving and ever increasing attention both in research activities and in the context of Energy Intensive Industries (EIIs) that are actively committed to reduce resources and energy consumptions in their processes. These actions aim at both reducing the environmental footprint of production processes and improving their efficiency, resulting in natural resources, energy and costs savings. In particular, development and implementation of new technical solutions and operating practices related to IS and EE are linked to ongoing technological upgrades, which involve both production processes and auxiliary services. For instance, some

\footnotetext{
it 15th International Conference on Society \& Materials, SAMEcoSD-15, Virtual, 10-11 May 2021.

* e-mail: valentina.colla@santannapisa.it
}

significant enabling technologies (e.g., novel treatment processes for by-product valorization, water purification and energy transformation, advanced waste heat recovery systems, and Carbon Capture, Storage and Utilization) pave the way to IS solution. All areas of the process industries can be affected, by involving all workers' categories, from top management to technical personnel and plant operators. In addition, some technologies in Information Communication Technology (ICT) enable information exchange between different companies and among companies and stakeholders, resulting in improving of cross-sectorial cooperation.

The present paper describes part of the work developed in the early stage of a current Erasmus + project entitled "Skills Alliance for Industrial Symbiosis: A Cross-sectoral Blueprint for a Sustainable Process Industry (SPIRESAIS)". The project aims at developing an industry-driven and proactive skills strategy to assist the implementation and exploitation of IS and EE in the EIIs. An assessment of 
current state of IS and EE solutions implementation in the European process industry is carried out, by analysing forthcoming technologies and taking into account the major levers of the Circular Economy (CE) transformation. In addition, the project aims at providing a consolidated approach to anticipate skills demands for IS and EE, for a more proactive cross-sectorial cooperation and integration. In particular, the main objectives consist in a proactive identification of skills needs and demands, to build appropriate training and curricula, as well as in identifying, developing and promoting sectoral recruitment and upskilling schemes.

This paper presents the investigation of the current state of the IS and EE in the European Process Industry through the analysis of the results from a survey carried out inside the SPIRE-SAIS project. The performed questionnaire, distributed among companies, is based on ongoing and past experiences, expectations and foreseen challenges related to the possible adoption of the IS and EE solutions in the involved companies. In addition, the resulting impact of these actions on workforce was considered. This questionnaire was addressed to employees of the European process sectors and was launched in July 2020 until the end of 2020 .

The paper is organized as follows: Section 2 presents an overview of IS and EE in EEIs; Section 3 presents the structure of the questionnaire. The survey results are discussed in Section 4, by considering current levels of IS and EE implementation, economic, environmental and social benefits as well as impacts on workforce and training programs. Finally, Section 5 provides some concluding remarks.

\section{Industrial Symbiosis and Energy Efficiency in European energy intensive industries}

\subsection{Industrial symbiosis}

IS concerns re-use of residual materials (i.e., waste and byproducts), water and energy of a production process as inputs of other traditionally available processes, within the same company or among different companies [1]. IS can be a business opportunity for ecological innovation [2] and its implementation can lead to lower production costs while in parallel creating environmental and social benefits for the involved companies $[3,4]$. For this reason, IS represents an effective strategy which supports the transition to CE [5], and the importance of IS is underlined in the Circular Economy Action Plan from the European Commission (EC) [6]. In addition, the European Green Deal, which is the new agenda of Europe for sustainable growth, represents a new strategy for a more sustainable management of materials and resources and more rational practices in waste management and recycling [7]. The European Green Deal aims at achieving social prosperity, resource efficiency and economic competitiveness in EU. Supported and recommended by the EC [8], several countries are committed to introduce IS in their agenda. Clearly, for companies the main driver for adopting IS practices is represented by potential economic benefits. On the other hand, cooperation among companies can be promoted and facilitated not only by economic drivers (e.g., reduction of raw materials and waste costs, revenue generation), but also by geographical, legislative and political (e.g., regulatory pressure, landfill tax), technical, operational, logistical, market related, and environmental factors. However, a lack of awareness is still observed in many companies in introducing IS-based approaches into their business practices [9], although, over the last few years, several contributions on IS business models have been provided. On the other hand, IS development is still hampered by environmental (e.g., national and international constraints, low taxes for disposal, etc.), economic (e.g., lower price of raw materials compared to industrial by-products produced, low transportation costs), technical, regulatory/legal, organizational, social, and cultural barriers. However, strategic actions can overcome such barriers. Clear and consistent regulations and policies can promote IS implementation. Economic incentives can be a further driver, while facilitators play a key role in assisting companies to set up cooperation and in organizing training to employees $[10,11]$. Finally, research activities on innovative technologies can provide new opportunities and result in new jobs and new synergies among industrial sectors [12].

Concerning IS implementation in different EIIs, the steel sector can provide interesting examples of byproducts and energy transactions with other sectors [13]. Some residues from steel production processes can be internally recycled, others can be used in other sectors (e.g., iron oxides and slags are used in Portland cement production, while zinc oxides from the EAF process, can be used as raw material in the Waelz process [14]). Iron and steel slags are usually reused in cement production (e.g., BF slag, after fast cooling, results in a glassy and granular material to be used for Portland cement production and Ground Granulated Blast Furnace Slag (GGBS) is used in cement concrete [15]). Furthermore, steel slags can be used in soil amendments, such as in acidic soils by increasing $\mathrm{pH}$ and in soft soils by improving their physical properties [16]. Among non-ferrous metals sector, the aluminum industry is also fully committed to recycling practices for achieving the full circularity, as aluminum can be recycled without losing its original properties. This metal in Europe can reach recycling rates over $90 \%$ (automotive and building sectors), and $75 \%$ (aluminum cans) [17].

Together with the reduction of $\mathrm{CO}_{2}$ emissions and wastewater, also the ceramic sector is committed to recover and recycle production residues [18], which can be internally used by saving other raw materials, avoiding extraction, transport and use of large amount of natural materials [19].

\subsection{Energy efficiency}

The European process industry, mainly represented by the EIIs, is one of the largest energy users in EU. Over the last few decades, the energy consumption has doubled, due to both population growth and increased energy consumption pro-capita. In particular, global energy demand increased 
by $2.1 \%$ in 2017 , more than twice the growth rate in 2016 , and it is expected to further increase by $30 \%$ until 2040 [2022 . Currently $84 \%$ of energy production comes from fossil fuels (i.e., oil, coal, and natural gas) [23], that are responsible for more than $60 \%$ of worldwide emissions of $\mathrm{CO}_{2}$, which is the main cause of the global warming [24]. On this subject, the main challenge at the global level is to reduce $\mathrm{CO}_{2}$ emissions by $80 \%$ until 2050 [25,26]. This goal can be reached through drastic reduction of energy produced by fossil fuels but also by implementing new technologies for reaching energy efficiency practices. In particular, the main challenge consists in implementing low-carbon technologies and adopting renewable energy sources to reduce greenhouse gas (GHG) emissions and global warming. By using available technologies, $38 \%$ of $\mathrm{CO}_{2}$ reduction can be achieved, while Carbon Capture and Storage (CCS) and renewable energy technologies can reduce emissions to $19 \%$ and to $17 \%$, respectively [27].

On this subject, the EU regulations aim at reducing emissions, improving $\mathrm{EE}$ and encouraging renewable energy. The European Energy Union strategy is mainly focused on economic competitiveness and sustainability improvements as well as on emissions reductions and energy efficiency improvement. This strategy includes also the increase of supply security and job creation. On this subject, EC provided the recent 2030 Climate and Energy Policy [28] and the Energy Roadmap, which aims at reducing 80-95\% (compared to 1990) of GHGs emissions by 2050 [29]. In addition, the EU's 2020 strategy targets a smart, sustainable and inclusive growth through climate and energy efficiency [30]. Among European policies and frameworks, the European Green Deal [7] also concerns EIIs, including different key sectors, such as steel, chemicals and cement. On this subject, EIIs are committed to improve their performances through upgrade technologies or application of new ones. In addition, other implementable measures include good management, education and behavior changes. However, in the next few decades EIIs are expected to increase their energy consumption worldwide. For instance, in the steel and chemical sectors, such increase could be due to both steel production increase and limited applications of emerging EE technologies. On the other hand, in the next decades (2030 to 2040) energy consumption is expected to be constant due to commercialization of breakthrough technologies [31].

As far as other EEIs are concerned, the non-ferrous metals production will decrease, as this sector does not provide new investments in production capacity and does not expand its production outside the EU. In addition, this trend will be supported by the production increase of secondary metal through improved recycling and recovery of useful scrap metal. In addition, the nonmetallic minerals sector is expected to remain constant by 2050. Lime and ceramics will decline, glass will be stable, while cement production will slightly increase [32]. For several EEIs energy represents the highest production cost, such as for ceramic sector. For this reason, in the next few decades, further investments are needed within the EEIs to reach the EE targets. However, some strategic sectors, such as steel, are continuously committed to reduce energy consumptions and to improve $\mathrm{EE}$ in its production processes [33]. An example of EE procedures applied to gas network management in steelworks consists in the use of Machine Learning (ML)-based models to optimize gases distribution, by considering possible interactions [34,35]. In addition, Key Performance Indicators (KPIs) can be used for monitoring gas management efficiency, and for defining overall economic and environmental objectives [36]. Simulation tools based on KPIs assessment and Aspen Plus ${ }^{\circledR}$ models $[37,38]$ can be applied for improving the sustainability of Electric Arc Furnace (EAF)-based steel production [39]. The mineral sector is also committed to reduce energy consumption in its production processes, to promote EE initiatives [40] and to increase the use of renewable energy sources [41]. The cement sector is responsible of more than $5 \%$ of global emissions of $\mathrm{CO}_{2}$, but also of $\mathrm{SO}_{2}, \mathrm{NO}_{\mathrm{x}}$ and other pollutants [42]. Here EE improvements are mainly focused in decreasing energy consumption and $\mathrm{CO}_{2}$ emissions, while preserving high quality of production processes [43]. The ceramics sector is also committed to process and product innovations targeting at further reductions in the energy demands [44].

\section{Structure of the questionnaire}

The questionnaire developed inside SPIRE-SAIS to investigate the current state of IS and EE in the European Process Industry, includes a set of questions, but they were not all mandatory. To avoid unnecessary answers, some questions are shown to the respondent under conditions of the previous question. Considering, for instance, the question "Does your company apply principles of the Energy Efficiency?", if the respondent answers "Not Yet", he/she is not required to answer to the following questions, such as "What is the current level of Energy Efficiency in your Company?". Conversely, the respondent is asked to answer to other questions, which aim at evaluating the awareness of potential benefits of EE in the company. The questionnaire is articulated into four main sections:

- Section I concerns the ongoing and foreseen implementation of IS and EE and the expected benefits. In this section, two subsections are included. Each of them is devoted to one of the covered topics, as companies might also implement or foresee to implement solutions and practices concerning only one of the two topics;

- Section II covers technical aspects, including envisaged resource synergies, adopted tools, main actors and areas involved in the ongoing or foreseen implementation of IS and EE. Since companies could be involved or foreseen to implement only one of IS and EE practices, similar but separate questions address the two topics. These questions are available to respondents, that have answered positively to the first questions in Section I, focused on the companies' involvement in aspects of IS and EE implementation;

- Section III concerns expected impacts of IS and EE on workforce. This section includes not only general questions, but also questions related to only one of the two key topics; 


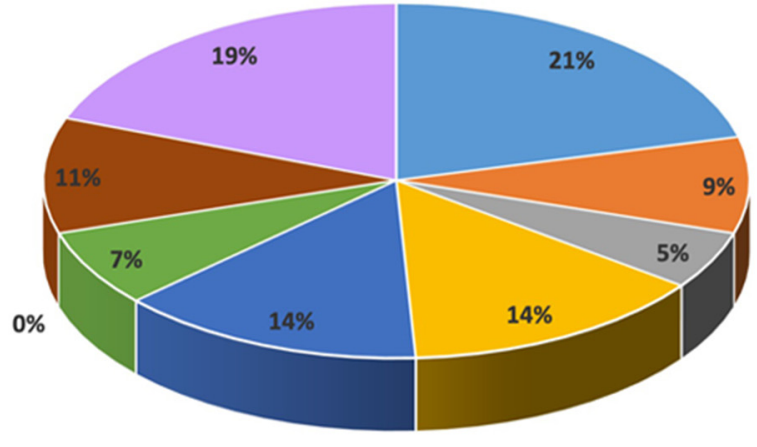

(a)
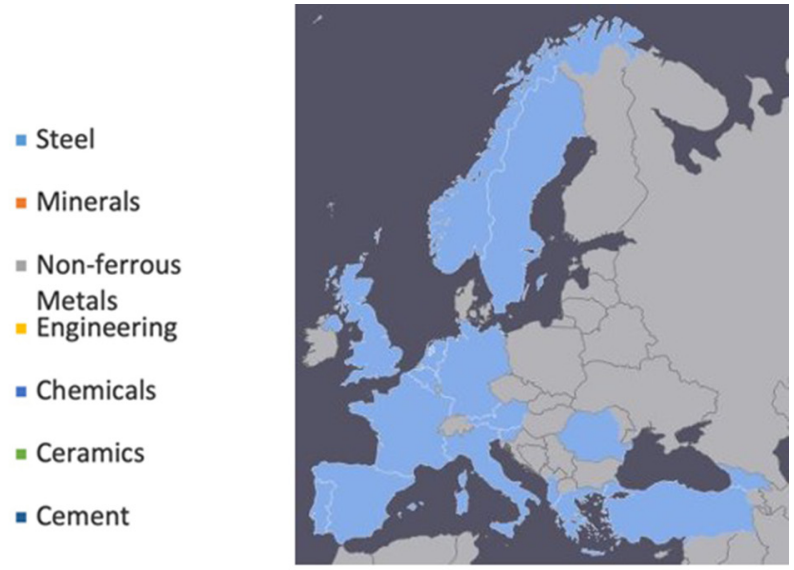

(b)

Fig. 1. (a) Distribution of the respondents among the different sectors; (b) geographical distribution of the respondents.

- Section IV is related to the collection of general information on the participants. Filling all the fields is not mandatory, only the sector and the dimension of the company represent the key information to be provided, and no personal information is required, while the name of the company can be provided only on a voluntary basis.

\section{Results}

Survey results are based on the analyzed sample including 65 valid answers and meaningful in terms of information completeness. The recruitment of participants was carried out both within the partners involved in the SPIRE-SAIS project, who in turn sent it to other companies. Although the sample was small, including 65 participants, a wide range of perspectives in terms of general information (i.e., country of origin of respondents, company size and product types) were covered. In particular, respondents come from several European sectors of process industry (see Fig. 1a) located in different countries, as shown in Figure 1b. Although participants belonged both to big companies and to Small and Medium Enterprises (SME), most of respondents came from large companies and involved different professional profiles. In particular, 57 companies participated in the survey, belonging to the main involved sectors, and representative of European process industries. Participants were representative of the targeted sectors and deeply involved in the main topics faced in the survey, such as General Manager, Head of Industrial Process Areas, Area Manager for Resources \& Recycling and processes, R\&D Technician, R\&D Manager, R\&D senior Technologist, Project Manager, HR Manager, Technical Manager, Energy coordinator, Employee, Technician, Project Manager, etc. In addition, different employees from the same company could answer the Questionnaire.

\subsection{Current level of Industrial Symbiosis and Energy Efficiency implementations}

According to survey results, within companies the current level of EE implementation is higher than IS ones, as shown in

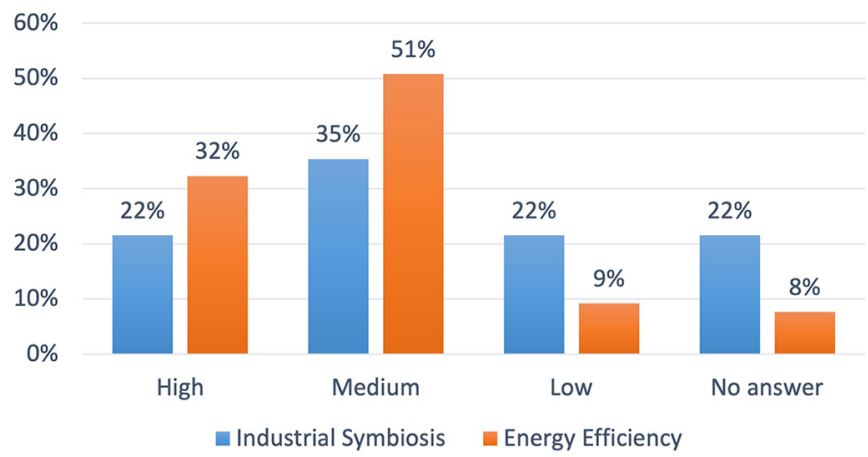

Fig. 2. Current levels of IS and EE implementation.

Figure 2. IS is of growing interest over the last years, but not so far developed and recognised within the companies yet. However, many respondents showed how their companies are committed to increase their efforts to implement both IS and $\mathrm{EE}$ concepts in the next few years, by also paying attention to investments in new technologies.

In the survey, barriers related on the application of IS practices are considered. Results show that the main barriers are related to cost of investments, integration of regional stakeholders, regulatory issues, outdated plants, infrastructure and equipment and cooperation challenges, as shown in Figure 3.

In addition, other barriers have been identified, which include administrative and regulatory issues related to material classification for transportation purposes, lack of real incentives for recycling of materials, lack of capability of industry to ensure a regular flow of material to recycle, difficulties in establishing a fair distribution of the benefits and costs across partners, and maturity of financial tools and structures. Finally, at national level, mainly characterized by small and medium-sized enterprises (SMEs), a further risk is represented by the limited possibilities of SMEs in investing in innovation/retrofitting. Therefore, cooperative business models should be promoted and implemented.

Concerning EE, the main identified barriers for companies are cost of investments and obsolete plants, followed by cooperation challenges, working across 


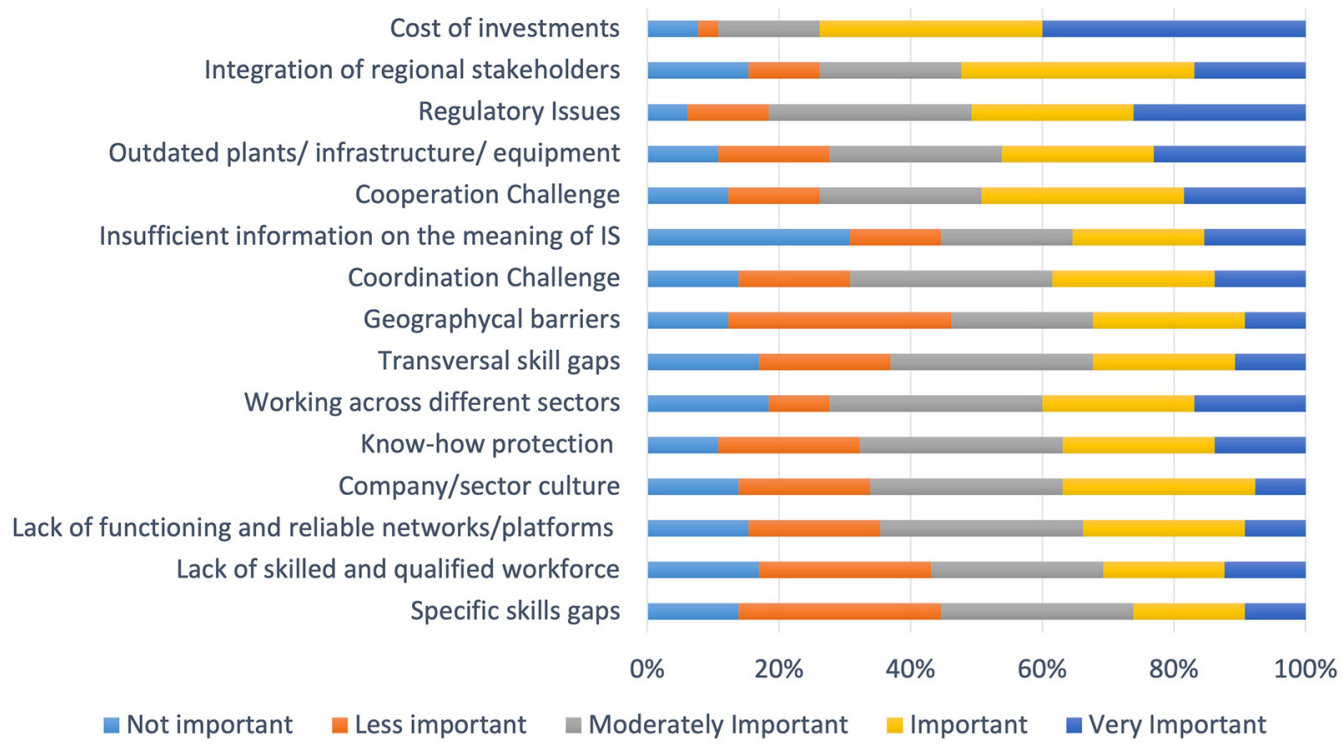

Fig. 3. Assessment of the barriers in the application of IS.

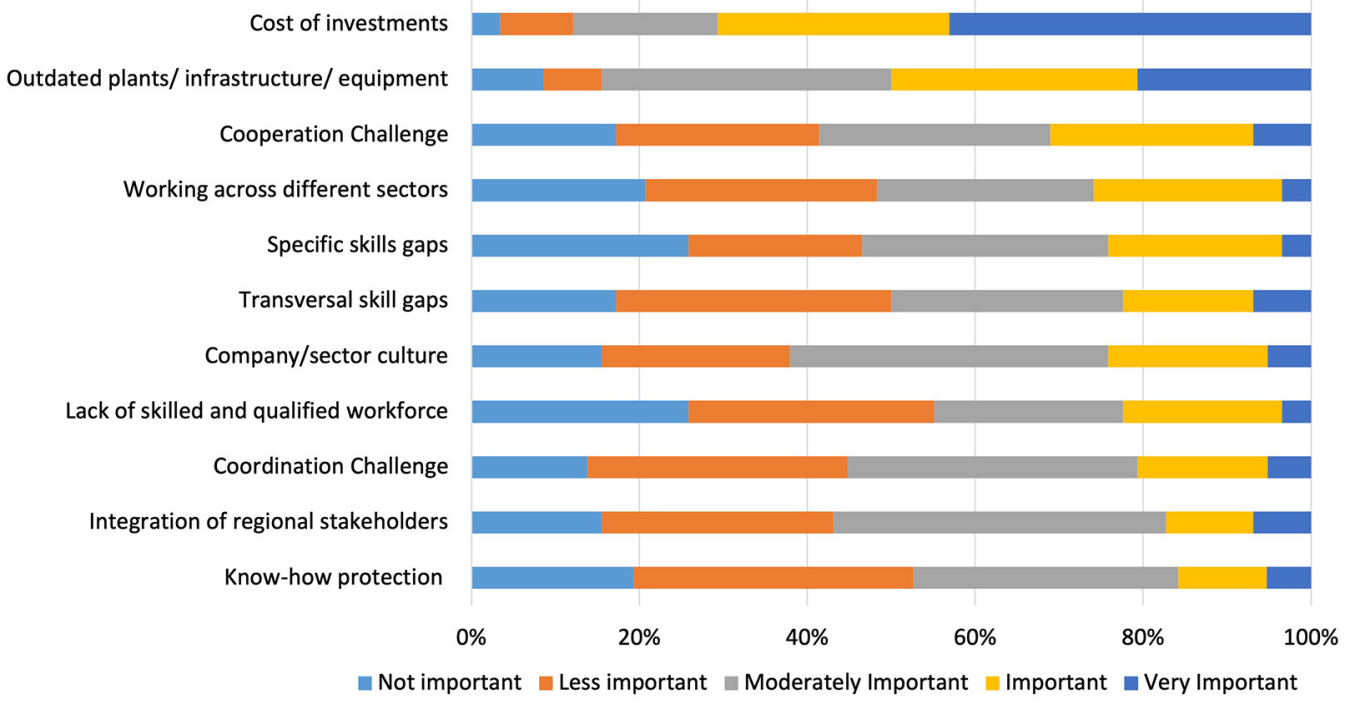

Fig. 4. Assessment of the barriers in the application of EE.

different sectors and skills gaps (see Fig. 4). A further issue is indicated in evolution of manufacturing and personnel habits. In addition, the incorporation of new solutions in a $24 / 7$ brown field situation can lead to disruptions and risks for the continuous production.

\subsection{Economic and environmental benefits}

The expected economic benefits from the application of IS practices mainly consist in reduction of costs for waste disposal, increased sustainability of the production process and increased overall competitiveness. In addition, the reduction of water consumption, also representing an environmental benefit, is highlighted as a further economic benefit. The application of EE practices is expected to lead to higher benefits related to overall energy efficiency and increased sustainability and competitiveness. These results are depicted in Figure 5, where the x-axis refers to the percentage of the respondents that, due to the possibility to multiple choice, selected different benefits. Other responses mainly included the following economic benefits: "developing new professional skills" and "reduction of water consumption".

On the other hand, concerning the environmental aspects, IS is expected to lead mostly to waste reduction, whilst EE leads to GHG emissions reduction. The application of both concepts is expected to reduce natural resources depletion and ecological footprint, such as depicted in Figure 6. Additionally it has to be mentioned, that IS is more dedicated to the reduction of by-products 


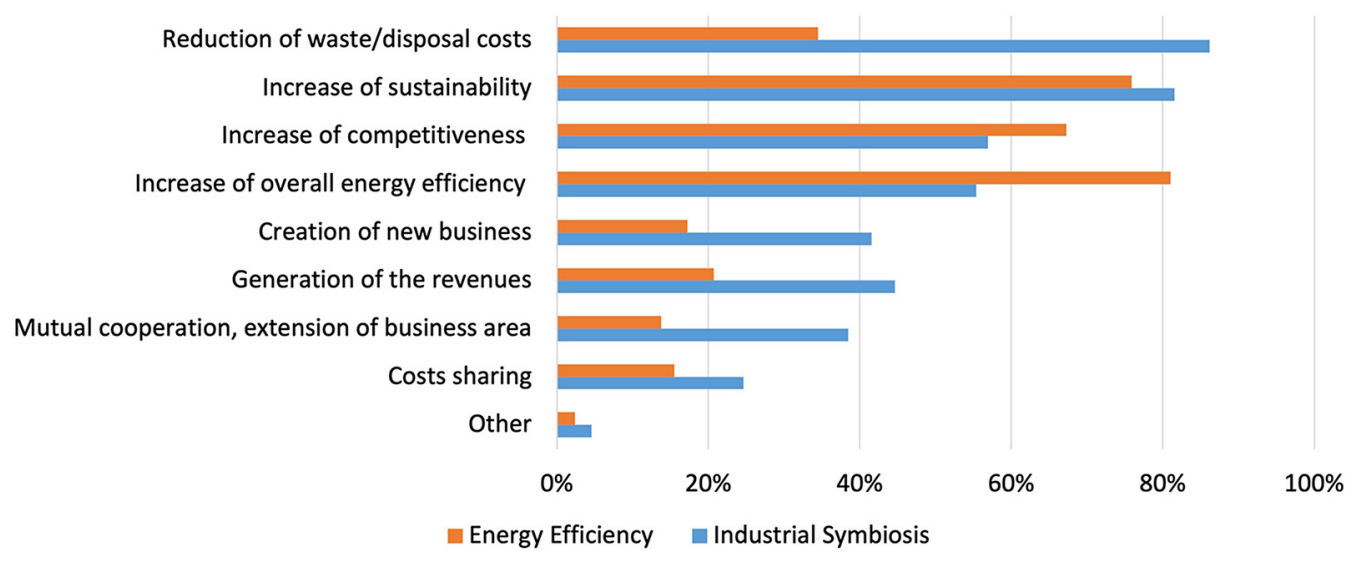

Fig.n 5. Expected economic benefits of IS and EE practices for companies.

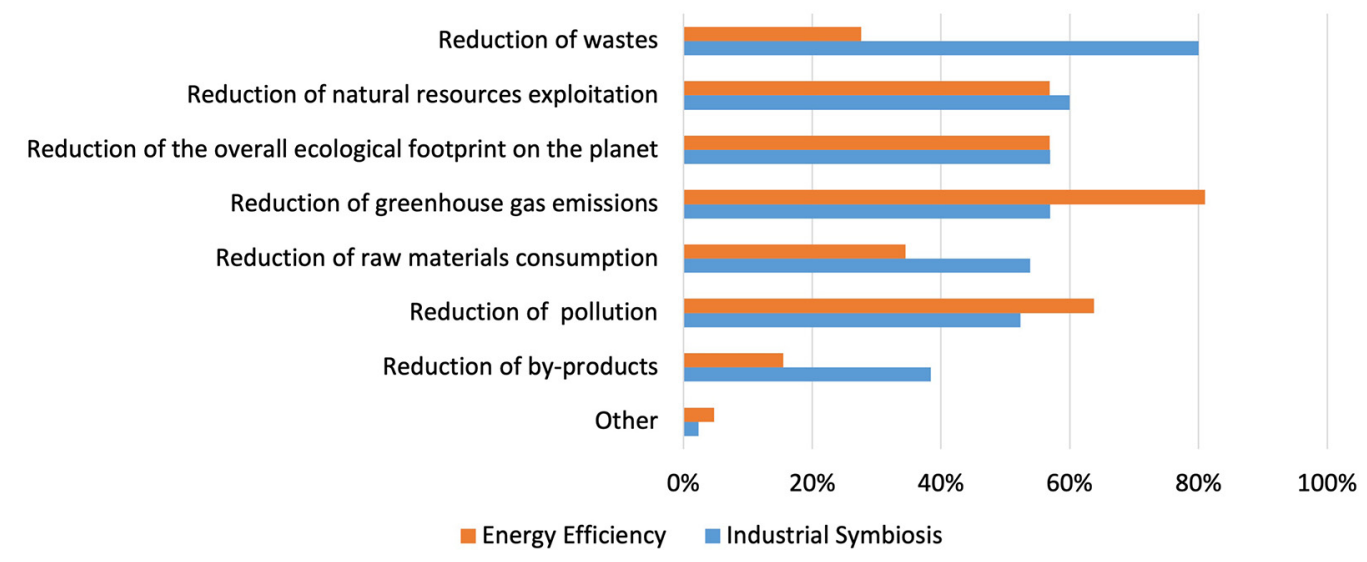

Fig. 6. Expected environmental benefits of IS and EE practices for companies.

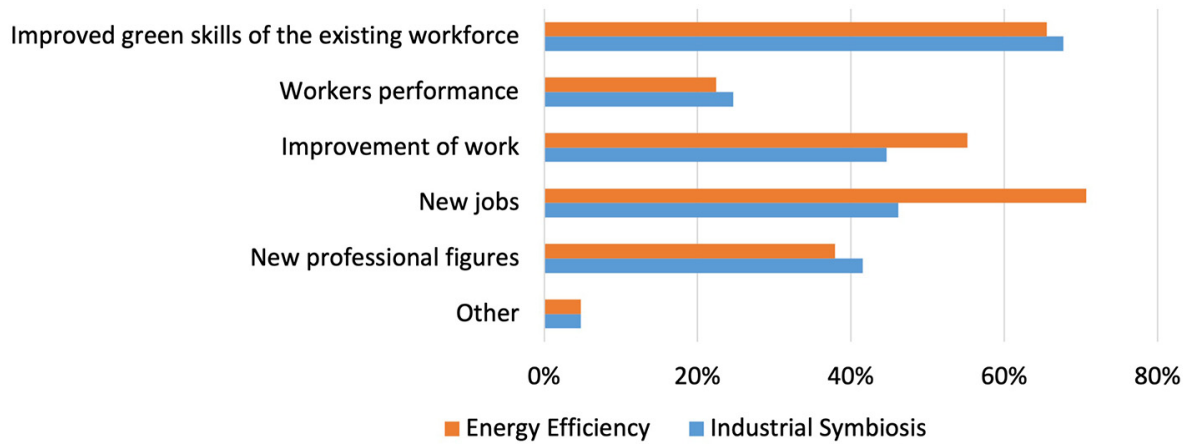

Fig. 7. Expected social benefits of IS and EE practices for companies.

and raw material consumption than EE. In addition, another environmental benefit mentioned is represented by a "better integration of industrial production with social civil society".

\subsection{Social benefits}

Concerning social aspects, the implementation of both IS and EE concepts in company's activities is expected to improve working conditions and provide benefits on green skills (see Fig. 7). Further responses include "proud, young workers" and "green image". Furthermore, results show higher expectations on IS about new jobs creation and workers' performance.

IS is also expected to improve the social perception of industrial activities, whilst EE is perceived as a set of activities leading to reduction of global environmental impact. In addition, the participants think that applying IS and EE concepts can produce both reduction of environmental impacts and social benefits, such as new jobs and benefits to the present and future community of their own regions. 


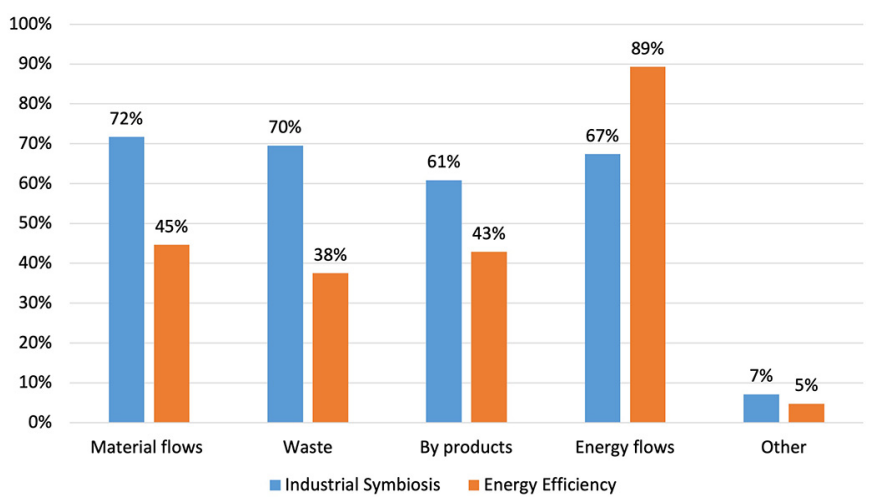

Fig. 8. Resource synergies involved in the application of IS and EE practices.

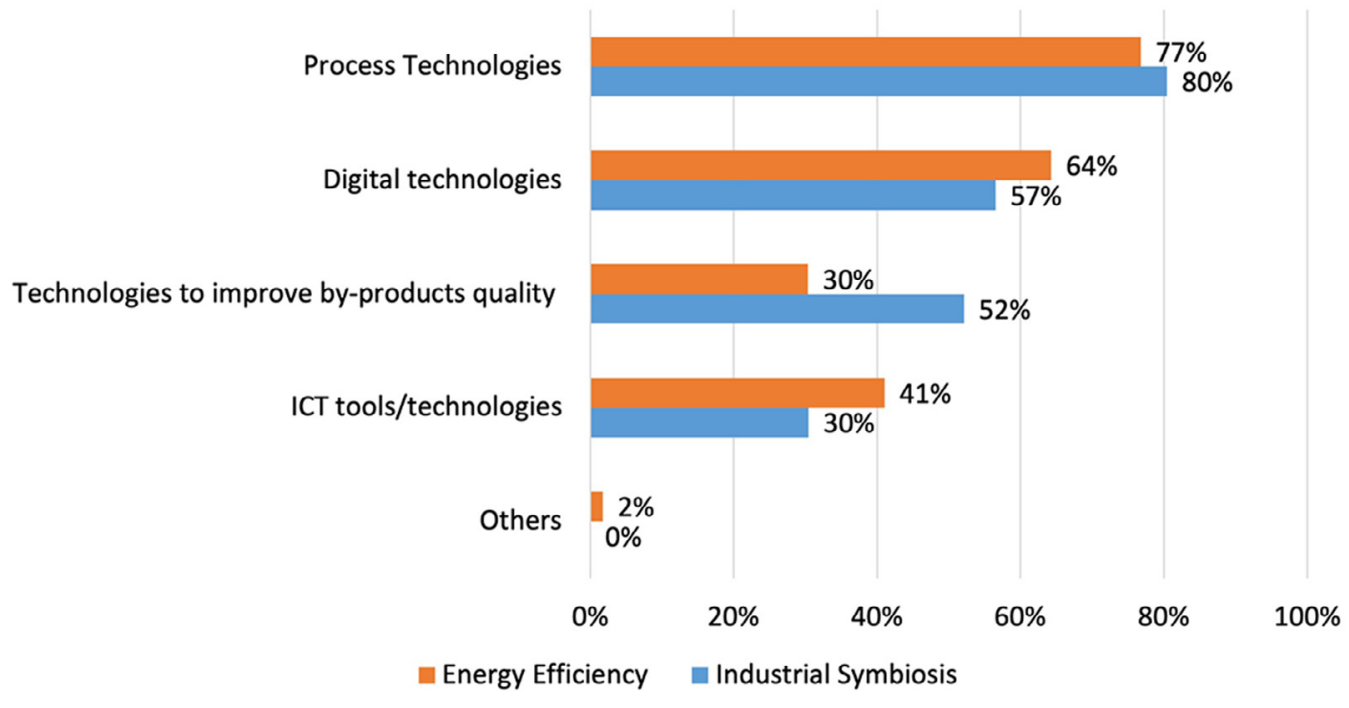

Fig. 9. Main tools/technologies adopted for the IS and EE implementation.

The respondents belonging to companies already involved in IS and EE practices consider that all the resource synergies are significantly affected by IS, while EE mostly affects energy flows, although it also affects other flows. In addition, the smallest percentage includes water use and $\mathrm{CO}_{2}$ emissions. This is shown in Figure 8, where yaxis refers to the percentage of participants selecting each resource, being multiple choices allowed.

Concerning tools and technologies that can be used for implementing IS and EE practices the respondents' choices are mainly focused on Process Technologies and Digital Technologies. They consider these technologies useful, as their companies are already involved in such practices. In particular, ICT tools are considered more relevant for EE, while by-products treatment technologies are more relevant for IS. The main tools and technologies adopted for the IS and EE implementation are shown in Figure 9 (multiple choices were possible), where a further answer refers to retrofitting of the lines.

The main actors involved in IS and EE practices are the internal actors, such as Quality Managers and Energy Managers, but more than $50 \%$ of participants think that other industries in different sectors can play a relevant role. Local actors are considered more involved in EE than in IS. Other identified actors are the regulators. Furthermore, the companies' areas where IS and EE are largely applied are the production process chain and the Energy Department. The Environmental and Sustainability Departments are also significantly involved, although mostly for IS implementation.

\subsection{Impact on the workforce}

The survey concerned also the foreseen impact on companies' workforces after introduction or more active implementation of IS and EE in the incoming 3-5 years. Figure 10 shows that job increases are expected, especially highly qualified profiles. Other identified impacts refer to new research directions for development of emerging technologies, such as digital processing methods (e.g., additive manufacturing, use of recycled materials for high tech applications) and digital technologies, attraction of young talents and development of new business lines, but also higher workload. In general a broad set of skills is 


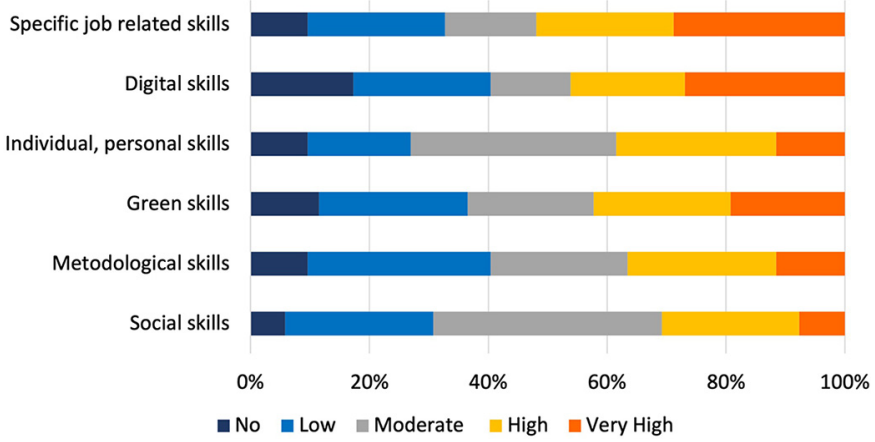

Fig. 10. Needs for skills updating for the application of IS and EE.

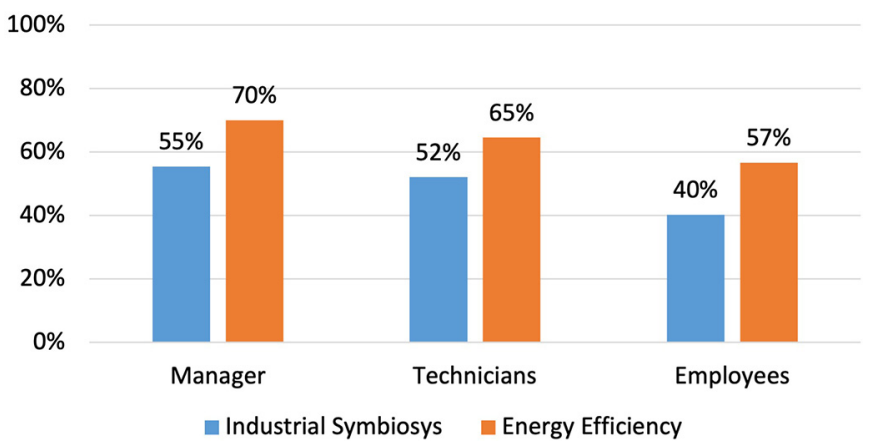

Fig. 11. Average percentage of different categories of workers that are aware of the needs of IS and EE.

needed. In particular, skills that mostly need to be updated in the incoming 3-5years are specific job-related skills, digital, green and personal skills. Other identified skills are regulatory skills and entrepreneurship.

Within the different working categories, compared to other Employees, Managers and Technicians are considered more aware of the needs of IS. In average more than $50 \%$ of the workers in all the categories are considered aware of the needs of $\mathrm{EE}$, and such percentage is particularly high for Managers (see Fig. 11). The overall awareness of the needs of EE appears to be higher than the awareness of the needs of IS.

\subsection{Training programs on IS and EE}

Concerning the training programs, the survey results show that no specific training programs are present in the participants' companies, especially on IS but also on EE. $47 \%$ of respondents declare that, over the last 12 months, in their companies no employee participated to trainings that strengthened his/her skills or provided knowledge related to IS. On the other hand, only $26 \%$ of respondents provide the same declaration concerning EE.

The survey shows that the level of skill of the companies' employees is generally lower for IS than for EE (see Fig. 12) and especially for IS it is often not known.

The respondents declaring that the level of skills of the employees is middle or high consider training on the job and non-formal training as the most common activities for improving skills, as shown in Figure 13. None of the participants declared that the employees received skills on IS by employing formal vocational education and training (VET) processes. In addition, the smallest percentage identified concerned "with implemented projects" as a further adopted mean to acquire skills.

The respondents perceive that relevant skill demands are faced due to IS implementation for any workers category. In addition, as shown in Figure 14, such demand is slightly higher for Technicians.

To adjust the above-mentioned skill gaps the main means considered by the respondents are internal and external training measures (see Fig. 15). Not to forget, about one third are also looking for recruiting new people. In addition, a small percentage indicated also "training on the job" and "I do not know".

Concerning EE, the skill demands faced by companies are considered relevant for any workers category. Nevertheless, this demand is slightly higher for Managers (see Fig. 16). The main means considered suitable to adjust the skill gaps are internal and external training measures, such as shown in Figure 17. A bit lower than in EE about $25 \%$ of the respondents are looking for recruiting additional staff. Finally, the smallest part of respondents answered "I do not know", "No" and "with implemented projects".

\section{Conclusions}

The analysis of the results of a public survey carried out in the early stage of the ongoing project SPIRE-SAIS allowed identification of significant trends and perceptions on current achievements in IS and EE in EIIs. IS and EE are receiving increasing attention in the companies and are perceived as opportunities, as they can lead to different kinds of benefits. The perceived level of implementation is higher for EE rather than for IS, but companies are committed to increase their future efforts toward both topics.

Some barriers for the implementation of both concepts were identified; not all workers are aware on how to implement IS and EE practices and solutions, although both concepts are perceived to generate skill demands in any category of workers. In particular, the resulting barriers for IS are:

- cost of investments;

- integration of regional stakeholders,

- regulatory issues;

- outdated plants, infrastructure and equipment;

- cooperation challenges.

On the other hand, the main barriers for EE are, as follows:

- cost of investments;

- outdated plants;

- cooperation challenges;

- working across different sectors;

- skills gaps.

The survey results show that the levels of skills of the company employees are generally lower for IS than for EE. In addition, training measures, which are implemented by 


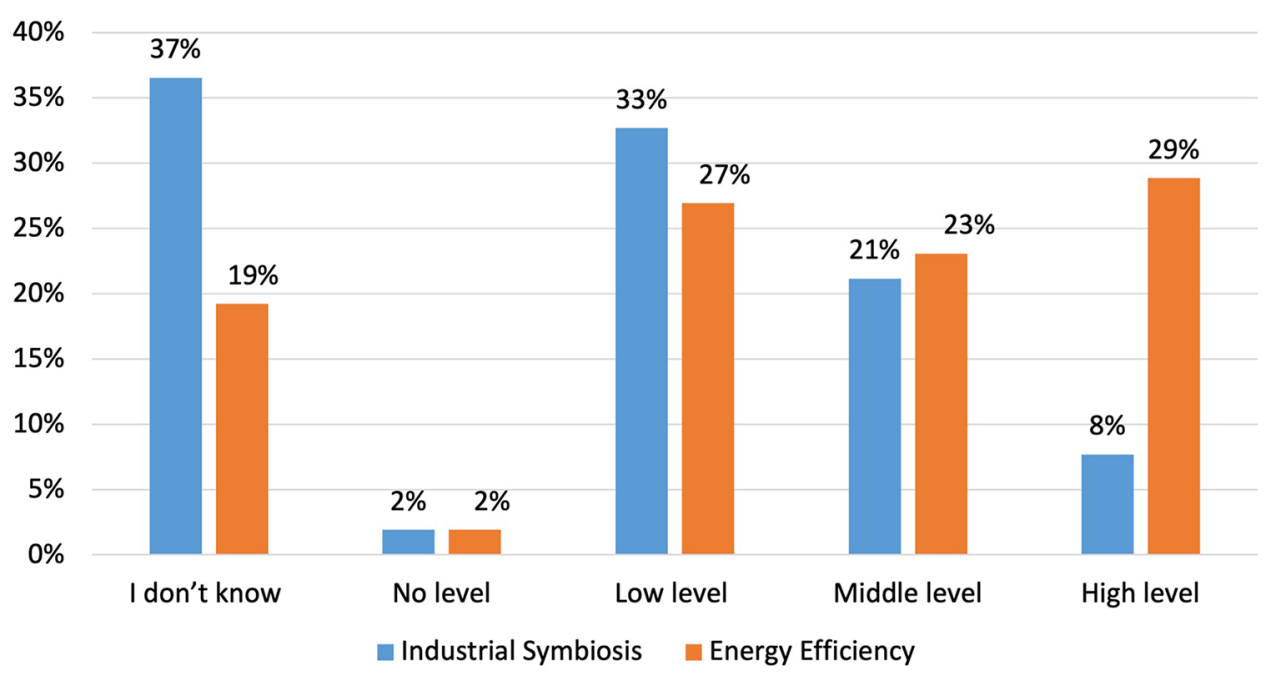

Fig. 12. Perceived level of skills of the company's employee on IS and EE.

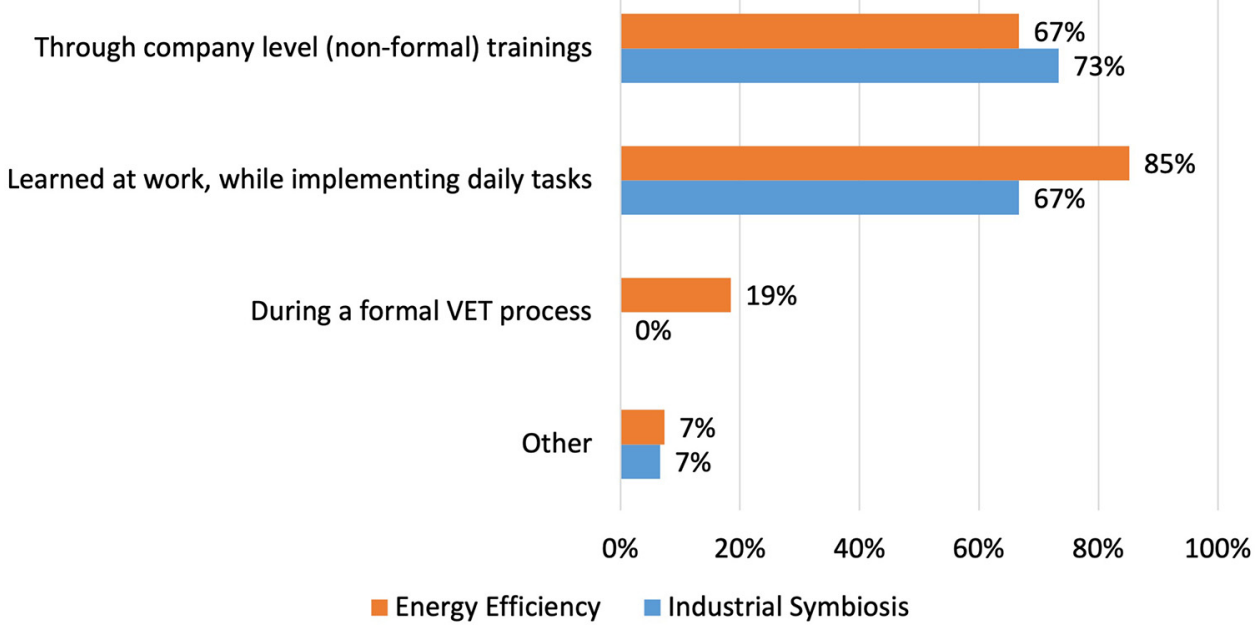

Fig. 13. Adopted means to acquire skills on IS and EE.

companies, are presently mostly not formal and unstructured. It was highlighted that in order to fill the emerging and future skill gaps the main solutions are identified in internal and external training activities. In the next 3 5 years the skills that mostly need to be updated are identified in specific job-related skills, digital, green and personal skills, while other useful identified skills are regulatory skills and entrepreneurship.

Finally, expectations and demands of the survey respondents are not only confirmed by the state-of-theart on the IS and EE in EIIs, but also fully in line with goals and initiatives pursued within the SPIRE-SAIS project.

In the future, to increase their competitiveness in Europe, EIIs should invest not only in new technologies for implementing IS and EE activities, but also in measures to adjust the related required skills. This will help to unfold the potential of new IS and EE solutions in the companies by improved skills, competences and experiences of the workforce as experts of the workplaces. Therefore, a longterm pro-active skills strategy can allow companies as well

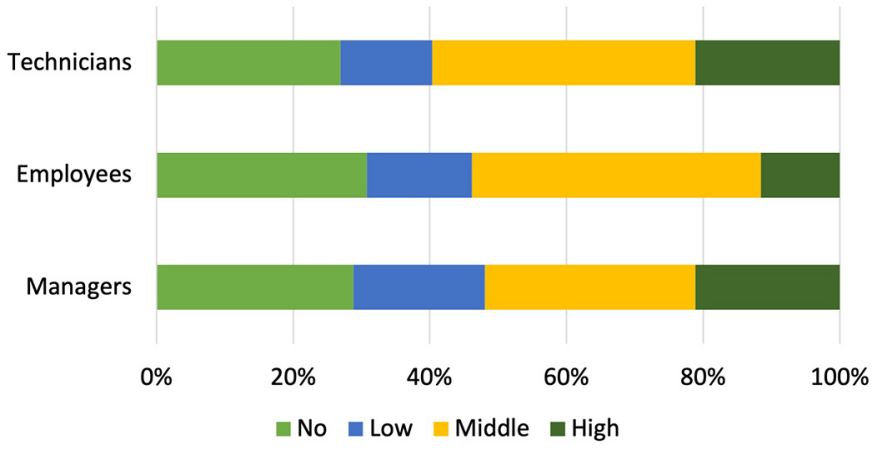

Fig. 14. Perceived skill demands because of IS.

as VET institutions adjusting their training programs. Attracting and retaining talented people as well as identifying and anticipating skills will represent the goal for making EEIs smarter, more inclusive and more sustainable. 


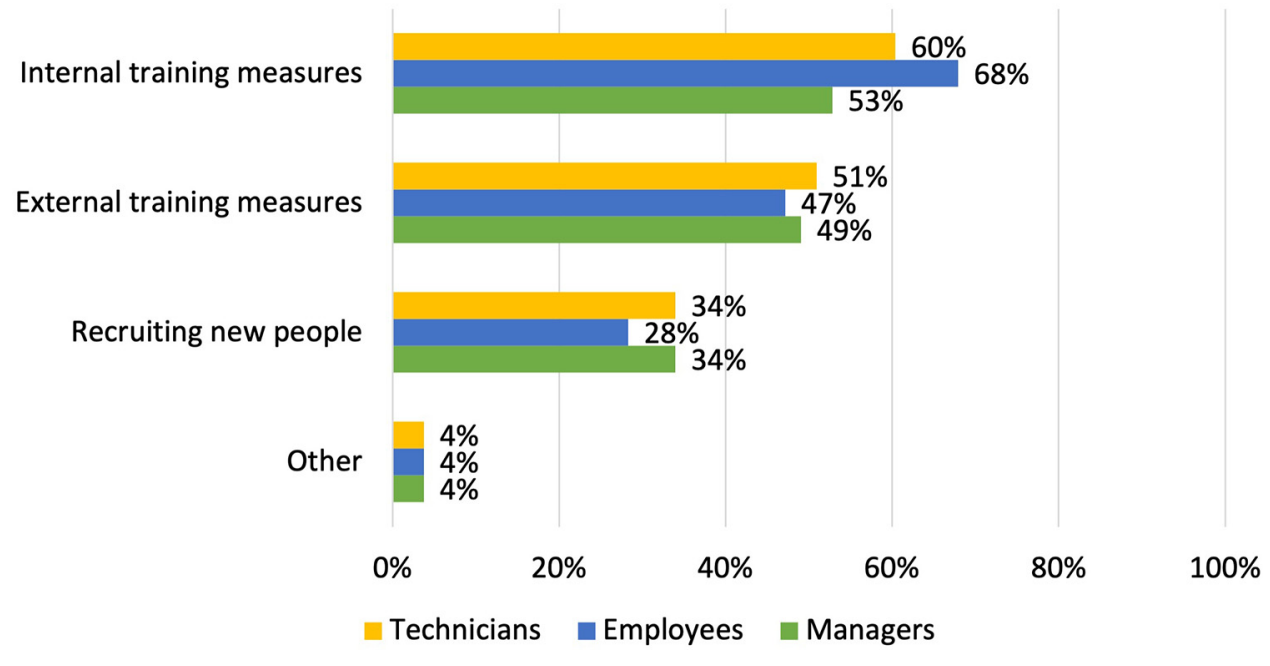

Fig. 15. Means to adjust skill gaps related to IS.

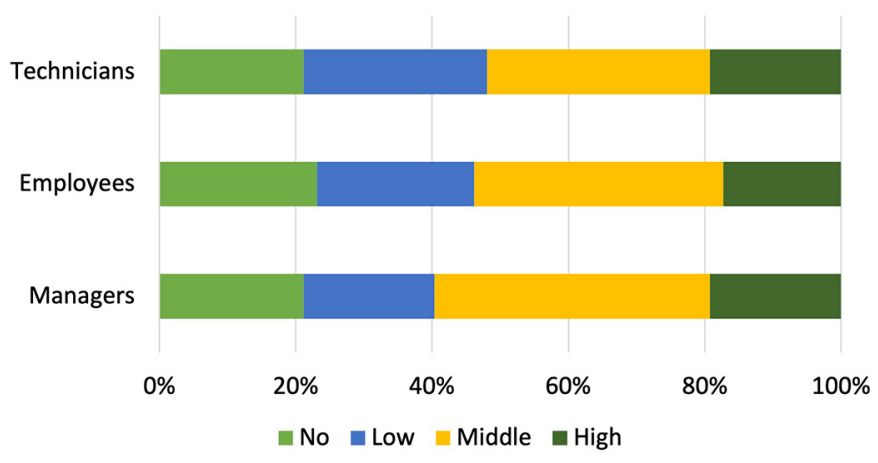

Fig. 16. Perceived skill demands because of EE.
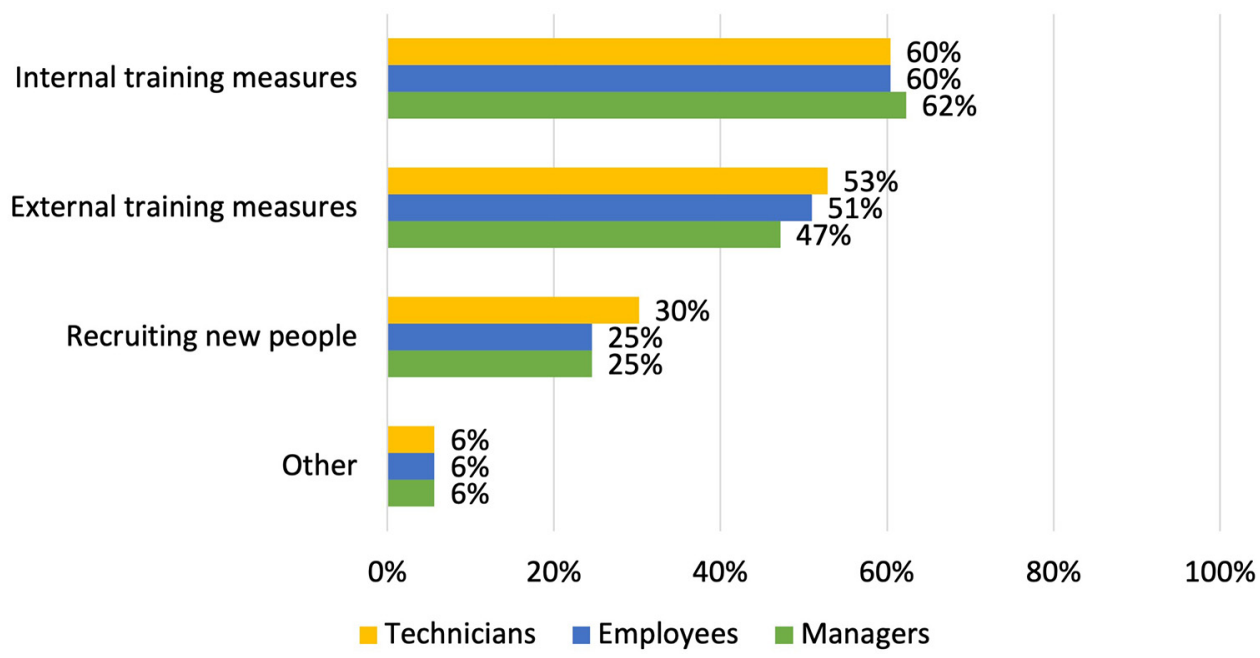

Fig. 17. Means to adjust skill gaps related to EE.

Acknowledgments. The research described in the present paper was developed within the project entitled "Skills Alliance for Industrial Symbiosis: A Cross-sectoral Blueprint for a Sustainable Process Industry (SPIRE-SAIS)" and is based on a preliminary deliverable of this project. The SPIRE-SAIS project is funded by Erasmus Plus Programme of the European Union, Grant
Agreement No. 612429-EPP-1-2019-1-DE-EPPKA2-SSA-B. The sole responsibility of the issues treated in the present paper lies with the authors; the Commission is not responsible for any use that may be made of the information contained therein. The authors wish to acknowledge with thanks the European Union for the opportunity granted that has made possible the development 
of the present work. The authors also wish to thank all partners of the project for their support and the fruitful discussion that led to successful completion of the present work.

\section{References}

1. M. Chertow, Industrial symbiosis: Literature and taxonomy, Annu. Rev. Energy Environ. 25, 313-337 (2000)

2. D. Lombardi, P. Laybourn, Redefining industrial symbiosis: Crossing academic-practitioner boundaries, J. Ind. Ecol. 16, 28-37 (2012), https://doi.org/10.1111/j.15309290.2011.00444.x

3. European Committee for Standardization, Industrial symbiosis: Core elements and implementation, Workshop Agreement, 2018

4. A. Neves, R. Godina, S.G. Azevedo, et al., The potential of industrial symbiosis: Case analysis and main drivers and barriers to its implementation, Sustainability 11, 7095 (2019)

5. European Commission, Closing the Loop-An EU Action Plan for the Circular Economy-COM (2015) 614 Final, European Commission, Brussels, Belgium, 2015

6. European Commission, Circular Economy Action Plan. For a cleaner and more competitive Europe, European Commission, Brussels, Belgium, 2020

7. European Commission, Communication No.640, 2019. The European Green Deal; (COM No. 640, 2019), Commission of European Communities, Brussels, Belgium, 2019

8. European Commission, Roadmap to a resource efficient Europe, Bruxelles, 2011

9. L. Fraccascia, M. Magno, V. Albino, Business models for industrial symbiosis: a guide for firms, Proc. Environ. Sci. Eng. Manage. 3(2), 83-93 (2016)

10. W. Jiao, F. Boons, Toward a research agenda for policy intervention and facilitation to enhance industrial symbiosis based on a comprehensive literature review, J. Clean. Prod., $14-25$ (2014)

11. H. Cervo, J.-H. Ferrasse, B. Descales, et al., Blueprint: A methodology facilitating data exchanges to enhance the detection of industrial symbiosis opportunities - Application to a refinery, Chem. Eng. Sci. 211 (2020), https://doi.org/ 10.1016/j.ces.2019.115254

12. T.A. Branca, B. Fornai, V. Colla, et al., The challenge of digitalization in the steel sector, Metals 10(2), 288 (2020)

13. S. Rosendahl, K. Lundkvist, B. Haase, et al., Establishing an industrial symbiosis - Key factors and time aspects in steel industry, Matériaux \& Techniques 107, 508 (2019)

14. T.A. Branca, V. Colla, D. Algermissen, et al., Reuse and recycling of by-products in the steel sector: Recent achievements paving the way to circular economy and industrial symbiosis in Europe, Metals 10, 345 (2020)

15. P. Ranya, P. Nagarajan, A. Shashikala, Eco-friendly Ggbs concrete: A state-of-the-art review, in: IOP Conference Series, Materials Science and Engineering, IOP Publishing, Bristol, UK, 012057 (2018)

16. T.A. Branca, C. Pistocchi, V. Colla, et al., Investigation of (BOF) converter slag use for agriculture in Europe. Rev. Metall. Int. J. Metall. 111, 155-167 (2014)

17. European Aluminium, Circular Aluminium Action Plan: A strategy for achieving aluminium's full potential for Circular Economy by 2030, 2020
18. Cerame-Unie, Ceramic Industry Roadmap: Paving the way to 2050, The European Ceramic Industry Association, 2012

19. W. Sancassiani, The ceramic product and production process and the Circular Economy, (2019)

20. International Energy Agency, Key world energy statistics, 2017

21. International Energy Agency, $\mathrm{CO}_{2}$ emissions from fuel combustion, 2017

22. International Energy Agency, Global energy \& $\mathrm{CO}_{2}$ status report, 2018

23. Fossil fuels still supply 84 percent of World energy-And other eye openers from BP's Annual Review, 2020

24. Field CB, Barros VR, eds, Climate change 2014-Impacts, adaptation and vulnerability: Regional aspects, Cambridge University Press, 2014

25. European Commission, Energy efficiency plan 2011, Brussels, 2011

26. J. Rogelj, M. den Elzen, N. Höhne, et al., Paris Agreement climate proposals need a boost to keep warming well below $2{ }^{\circ} \mathrm{C}$. Nature 534, 631-639 (2016)

27. International Energy Agency, Energy technology perspectives: Scenarios \& strategies to 2050, 2010, https://doi.org/ 10.1049/et:20060114

28. European Commission, Roadmap for moving to a competitive low-carbon economy in 2050, 2011

29. European Commission, Energy roadmap 2050, 2012

30. European Commission, Communication No. 2020, Europe 2020 - A Strategy for smart, sustainable and inclusive growth (COM No. 2020, 2010), Commission of European Communities, Brussels, Belgium, 2010

31. J. Malinauskaite, H. Jouhara, L. Ahmad, et al., Energy efficiency in industry: EU and national policies in Italy and the UK, Energy 172, 255-269 (2019)

32. ICF International, Study on energy efficiency and energy saving potential in industry and on possible policy mechanisms, 2015

33. K. He, L. Wang, A review of energy use and energy-efficient technologies for the iron and steel industry, Renew. Sustain. Energy Rev. 70, 1022-1039 (2017)

34. I. Matino, S. Dettori, A. Castellano, et al., Machine learningbased models for supporting optimal exploitation of process off-gases in integrated steelworks, in: Advances in Intelligent Systems and Computing, 1338, Springer, Cham, 2021, https://doi.org/10.1007/978-3-030-69367-1_9

35. I. Matino, S. Dettori, V. Colla, et al., Forecasting blast furnace gas production and demand through echo state neural network-based models: Pave the way to off-gas optimized management, Appl. Energy 253, 113578 (2019), https://doi.org/10.1016/j.apenergy.2019.113578

36. V. Colla, I. Matino, S. Dettori, et al., Assessing the efficiency of the off-gas network management in integrated steelworks, Matériaux \& Techniques 107(1), 104 (2019)

37. V. Colla, I. Matino, F. Cirilli, et al., Improving energy and resource efficiency of electric steelmaking through simulation tools and process data analyses, Matériaux \& Techniques 104(6-7), 602 (2016)

38. I. Matino, V. Colla, S. Baragiola, Electric energy consumption and environmental impact in unconventional EAF steelmaking scenarios, Energy Proc. 105, 3636-3641 (2017)

39. I. Matino, V. Colla, S. Baragiola, Quantification of energy and environmental impacts in uncommon electric steelmaking scenarios to improve process sustainability, Appl. Energy 207, 543-552 (2017) 
40. J.A. Curry, M.J. Ismay, G.J. Jameson, Mine operating costs and the potential impacts of energy and grinding, Miner. Eng. 56, 70-80 (2014)

41. B. McLellan, G. Corder, D. Giurco, et al., Renewable energy in the minerals industry: A review of global potential, J. Clean. Prod. 32, 32-44 (2012)

42. F. Schorcht, I. Kourti, B.M. Scalet, et al., Best available techniques (BAT) reference document for the production of cement, lime and magnesium oxide, European Commission Joint Research Centre Institute for Prospective Technological Studies, Luxembourg, 2013

43. A. Mokhtar, M. Nasooti, A decision support tool for cement industry to select energy efficiency measures, Energy Strategy Rev. 28, 100458 (2020)

44. Industrial decarbonisation \& energy efficiency roadmaps to 2050-Ceramic Sector, 2015

Cite this article as: Teresa Annunziata Branca, Valentina Colla, Barbara Fornai, Alice Petrucciani, Maria Ilaria Pistelli, Eros Luciano Faraci, Filippo Cirilli, Antonius Johannes Schröder, Current state of Industrial Symbiosis and Energy Efficiency in the European energy intensive sectors, Matériaux \& Techniques 109, 504 (2021) 